\title{
High body mass index is a significant risk factor for the progression and prognosis of imported COVID-19: a multicenter, retrospective cohort study
}

Huan Cai ${ }^{\dagger}$, Lisha Yang ${ }^{\dagger}$, Yingfeng Lư ${ }^{\dagger}$, Shanyan Zhang, Chanyuan Ye, Xiaoli Zhang, Guodong Yu, Jueqing Gu, Jiangshan Lian, Shaorui Hao, Jianhua Hu, Yimin Zhang, Ciliang Jin, Jifang Sheng, Yida Yang ${ }^{*}$ and Hongyu Jia

\begin{abstract}
Background: Coronavirus disease 2019(COVID-19) has spread worldwide. The present study aimed to characterize the clinical features and outcomes of imported COVID-19 patients with high body mass index (BMI) and the independent association of BMI with disease severity.

Methods: In this retrospective cohort study, 455 imported COVID-19 patients were admitted and discharged in Zhejiang province by February 28, 2020. Epidemiological, demographic, clinical, laboratory, radiological, treatment, and outcome data were collected, analyzed and compared between patients with $\mathrm{BMI} \geq 24$ and $<24$.

Results: A total of 268 patients had BMI $<24$, and 187 patients had BMI $\geq 24$. Those with high BMI were mostly men, had a smoking history, fever, cough, and sputum than those with $\mathrm{BMI}<24$. A large number of patients with $\mathrm{BMI} \geq 24$ were diagnosed as severe/critical types. Some biochemical indicators were significantly elevated in patients with $\mathrm{BMI} \geq 24$. Also, acute liver injury was the most common complication in these patients. The median days from illness onset to severe acute respiratory syndrome coronavirus 2 detection, duration of hospitalization, and days from illness onset to discharge were significantly longer in patients with $\mathrm{BMI} \geq 24$ than those with $\mathrm{BMI}<$ 24. High BMI, exposure to Wuhan, any coexisting medical condition, high temperature, C-reactive protein (CRP), and increased lactate dehydrogenase (LDH) were independent risk factors for severe/critical COVID-19. After adjusting for age, sex and above factors, BMl was still independently associated with progression to severe/critical illness $(P=$ 0.0040). Hemoglobin, alanine aminotransferase (ALT), CRP, and serum creatinine (Scr) were independent risk factors associated with high BMI.

(Continued on next page)
\end{abstract}

\footnotetext{
* Correspondence: yidayang65@zju.edu.cn; jiahongyu@zju.edu.cn

${ }^{\dagger}$ Huan Cai, Lisha Yang and Yingfeng Lu are co-first authors.

State Key Laboratory for Diagnosis and Treatment of Infectious Diseases,

National Clinical Research Center for Infectious Diseases, Collaborative

Innovation Center for Diagnosis and Treatment of Infectious Diseases,

Department of Infectious Diseases, The First Affiliated Hospital, Zhejiang

University of Medicine, 79 Qingchun Rd, Hangzhou, China
}

(c) The Author(s). 2021 Open Access This article is licensed under a Creative Commons Attribution 4.0 International License, which permits use, sharing, adaptation, distribution and reproduction in any medium or format, as long as you give appropriate credit to the original author(s) and the source, provide a link to the Creative Commons licence, and indicate if changes were made. The images or other third party material in this article are included in the article's Creative Commons licence, unless indicated otherwise in a credit line to the material. If material is not included in the article's Creative Commons licence and your intended use is not permitted by statutory regulation or exceeds the permitted use, you will need to obtain permission directly from the copyright holder. To view a copy of this licence, visit http://creativecommons.org/licenses/by/4.0/ The Creative Commons Public Domain Dedication waiver (http://creativecommons.org/publicdomain/zero/1.0/) applies to the data made available in this article, unless otherwise stated in a credit line to the data. 
(Continued from previous page)

Conclusions: Contrasted with the imported COVID-19 patients with BMI $<24$, high proportion of COVID-19 patients with $\mathrm{BMI} \geq 24$ in our study, especially those with elevated CRP and LDH, developed to severe type, with longer hospitalization duration and anti-virus course. Thus, high BMI is a risk factor for the progression and prognosis of imported COVID-19.

Keywords: High BMI, COVID-19, Risk factor, Progression, Prognosis

\section{Background}

Coronavirus disease 2019 (COVID-19) has brought a major social and medical challenge for the whole world since the end of December 2019 [1-5]. A novel coronavirus, officially named as severe acute respiratory syndrome coronavirus 2 (SARS-CoV-2), was identified as the pathogen of COVID-19, which causes acute respiratory distress syndrome (ARDS), multi-organ failure, and other severe complications [4, 6]. By January 17, 2021, over 93 million cases were confirmed, and 2.0 million patients died worldwide due to the disease. Moreover, a total of 23,334,423 cases were confirmed and 389,084 patients died in the United States [7]. Therefore, undoubtedly, COVID-19 has become a major global public health threat.

Angiotensin-converting enzyme 2 (ACE2) was identified as the surface receptor for SARS-CoV-2 [8]. ACE2 is widely expressed in various organs and tissues, including lungs, cardiovascular system, kidneys, gut, bladder and brain [9-12], which might explain the multiple organ failure in some COVID-19 patients. Surprisingly, a recent study suggested that ACE2 expression in adipose tissue was higher than that in lung tissue [13]. Notably, no difference was detected in the level of ACE2 expression in adipocytes and adipose progenitor cells between obese and non-obese individuals [14]. However, since obese individuals have abundant adipose tissue to express a larger amount of ACE2 proteins may expose them to higher risk status for COVID-19 [13]. Furthermore, adipose tissue serves as a reservoir for influenza $\mathrm{A}$ virus, human immunodeficiency virus (HIV), cytomegalovirus, human adenovirus Ad-36, Trypanosoma gondii, and Mycobacterium tuberculosis [15]. Therefore, COVID-19 might also infect adipose tissue and then spread to other organs.

The number of obese people worldwide has tripled since 1975. In 2016, more than 1.9 billion adults $>18$ year-old were overweight, among which over 650 million were obese [16]. Overweight/obesity is well acknowledged as a risk factor for increased mortality due to heightened rates of heart disease, certain cancers, and musculoskeletal disorders [17]. Recently, the impact of obesity on infectious diseases has also been confirmed $[18,19]$. Therefore, these patients with high body mass index (BMI) might be at increased risk of COVID-19 and exhibit poor prognosis. However, few studies have explored the clinical findings of such patients. Therefore, this study aimed to report the epidemiological and clinical characteristics and outcomes of COVID-19 patients with high $\mathrm{BMI}$ and to investigate the association of high BMI with disease severity.

\section{Methods}

\section{Study participants}

The present retrospective cohort study focused on the epidemiological and, clinical characteristics and outcomes of imported COVID-19 patients with measured weight and height on admission; they were discharged before February 28, 2020, in designated hospitals of Zhejiang province, China. All patients with COVID-19 enrolled in this study were diagnosed according to the guidance formulated by the Chinese National Health Commission. This study was conducted in accordance with the guidelines of the Declaration of Helsinki and was approved by the Clinical Research Ethics Committee of the First Affiliated Hospital, College of Medicine, Zhejiang University.

\section{Data collection}

The original data were collected by the Health Commission of Zhejiang Province. Herein, we utilized epidemiological, clinical, laboratory, radiological, therapeutic, and outcome data from the medical records of patients. At least two physicians independently reviewed the data according to standardized case report form. If clinical data was ambiguous or missing, we confirmed the details through directly contacting with the local medical staff or patients' families. Laboratory confirmation of SARS$\mathrm{CoV}-2$ was test by real-time reverse transcriptionpolymerase chain reaction (RT-PCR) [20]. Laboratory data consisted of a complete blood count, coagulation function, blood biochemistry test (including electrolytes, renal and liver function), creatine kinase (CK), lactate dehydrogenase $(\mathrm{LDH}), \mathrm{C}$-reactive protein $(\mathrm{CRP})$, and procalcitonin. Meanwhile, other respiratory pathogens, such as SARS- CoV, Middle east respiratory syndrome coronavirus (MERS-CoV), influenza A virus (H1N1, H3N2 and H7N9), influenza B virus, respiratory syncytial virus, parainfluenza virus, and adenovirus, were also identified. Treatments included antiviral therapy, 
antibiotic therapy, corticosteroid therapy, immunoglobulin therapy, mechanical ventilation, extracorporeal membrane oxygenation (ECMO) therapy, continuous renal replacement therapy (CRRT) and intensive care unit therapy.

\section{Definition}

The severity of the disease was staged according to the diagnosis and treatment Protocol for COVID-19 Patients of Chinese (8th edition) [21], which was based on minor modification of the World Health Organization (WHO) standards. The subtypes were defined as follows. Mild type: clinical symptoms were mild, and there was no evidence of pneumonia in chest radiology; Moderate type: showing fever and respiratory symptoms with radiological findings of pneumonia; Severe type: meeting one of the following criteria: 1) Shortness of breath, respiratory frequency $\geq 30$ breaths/minute; 2) resting blood oxygen saturation $\leq 93 \%$; 3) partial pressure of arterial oxygen to fraction of inspired oxygen ratio $<300 \mathrm{mmHg}$; 4) radiographic progression, lung infiltration $>50 \%$ within 24-48 h; Critical type: meeting one of the following criteria: 1) severe respiratory failure requiring mechanical ventilation; 2) shock; 3) combined with other organ failure requiring intensive care treatment. The patient was discharged if the following criteria were fulfilled: 1) normalization of temperature for at least 3 days; 2) respiratory symptoms improved significantly; 3) lung infiltrates improved significantly in chest imaging; 4) SARS-CoV-2 RNA test negative in two consecutive respiratory specimens (sampling interval at least $24 \mathrm{~h}$ ). The date of illness onset was defined as the day of presentation of clinical symptoms. The date of confirmed COVID-19 was defined as the day of laboratory confirmation. According to the Chinese consensus on overweight/obesity medical nutrition therapy (2016) [22], underweight is defined as $\mathrm{BMI} \leq 18.5 \mathrm{~kg} / \mathrm{m}^{2}$, overweight is defined as $B M I \geq 24 \mathrm{~kg} / \mathrm{m}^{2}$, and obesity is defined as $\mathrm{BMI} \geq 28 \mathrm{~kg} / \mathrm{m}^{2}$. Glucose (Glu) refers specifically to fasting blood sugar $3.9-6.1 \mathrm{mmol} / \mathrm{L}$.

\section{Statistical analysis}

For continuous variable, mean (standard deviation, SD) was used for normally distributed data, while the median (interquartile range, IQR) was used if the data were skewed, followed by unpaired Student's t-test and Mann-Whitney U test for comparison. Categorical variables were expressed as number (\%) and compared by Pearson's chi-squared test or Fisher's exact test. Univariable logistic-regression analysis was utilized to identify the risk factors of Severe/Critical type pneumonia patients. All significant variables in univariable analysis was included in a multivariable logistic-regression model using the forward procedure: Wald method to identify independent predictors of severe/critical COVID-19 patients. The logistic-regression model was used to estimate the odds ratio (ORs) associated with BMI for the risk of progression to severe/critical illness after adjustment for pertinent variables. The ORs and 95\% confidence intervals (CIs) of the progression to severe/critical illness in each subgroup were estimated, and their interactions tested. Likewise, multivariate logistic-regression analysis was also performed using high BMI as the dependent variable, including all significant variables in univariable analysis. A two-sided $\alpha<0.05$ was considered statistically significant and SPSS (version 26.0) was used for all statistical analyses.

\section{Results}

\section{Demographic and epidemiological characteristics}

By February 28, 2020, a total of 565 COVID-19 patients were discharged in Zhejiang province, and BMI data of 455 patients were included in our retrospective study, 268 /455 were classified as underweight/ normal weight group (Group A: BMI $<24$ ), and the remaining187 comprised the overweight/obesity group (Group B: BMI $\geq 24$ ), with corresponding median (IQR) BMI of 21.62(20.20-22.86) $\mathrm{kg} / \mathrm{m}^{2}$ and $26.12(24.69-27.92) \mathrm{kg} / \mathrm{m}^{2}$, respectively (Table 1$)$. The mean age in Group A was significantly lower than that in Group B (43.3 (15.7 y) vs. 46.3 (13.3 y), respectively, $P=0.028)$. The proportion of male patients was significantly higher in Group B than in Group A (63.6\% vs. $36.2 \%, P<0.001)$. However, no significant difference was noted in the percentage of exposure history in the two groups. A total of 20 (10.7\%) patients in Group B were currently smoking, which was significantly higher than $14(5.2 \%)$ patients in Group $\mathrm{A}(P=0.029)$. The presence of any coexisting medical condition was also significantly higher in Group B than in Group A $(43.9 \%$ vs $25.0 \%, P<0.001)$, including the rate of hypertension $(25.7 \%$ vs $9.7 \%, P<0.001)$ and chronic liver disease $(7.5 \%$ vs $3.0 \%, P=0.028)$.

The most common symptoms in the two groups were fever and cough. Group B showed significantly higher rate of fever $(87.7 \%$ vs. $79.5 \%, P=0.022)$, cough $(72.7 \%$ vs. $61.6 \%, P=0.013)$ and sputum production $(42.2 \%$ vs. $32.5 \%, P=0.033$ ) than Group A. However, Group B showed a significantly lower rate of sore throat $(10.7 \%$ vs. $17.9 \%, P=0.034)$ and nasal obstruction $(2.7 \%$ vs. $7.5 \%, P=0.027$ ). Furthermore, no significant differences were detected in the percentages of myalgia, fatigue, gastrointestinal (GI) symptoms, and headache. The incubation period, days from illness onset to first medical visit, days from illness onset to confirm the diagnosis and days from illness onset to first hospitalization between the two groups were not statistically significant. During the disease course, a significantly greater number 
Table 1 Demographic and Epidemiological Characteristics of COVID-19 Patients with Different BMI

\begin{tabular}{|c|c|c|c|}
\hline Characteristics & $\begin{array}{l}\mathrm{BMI}<24(\text { Group } \mathrm{A}) \\
(N=268)\end{array}$ & $\begin{array}{l}\mathrm{BMI} \geq 24(\text { Group } B) \\
(N=187)\end{array}$ & $P$ value \\
\hline Age(years) & $43.3(15.7)$ & $46.3(13.3)$ & 0.028 \\
\hline Sex & & & $<0.001$ \\
\hline men & $97(36.2 \%)$ & $119(63.6 \%)$ & \\
\hline women & $171(63.8 \%)$ & $68(36.4 \%)$ & \\
\hline BMI $\left(\mathrm{kg} / \mathrm{m}^{2}\right)$ & $21.62(20.20-22.86)$ & 26.12(24.69-27.92) & $<0.001$ \\
\hline \multicolumn{4}{|l|}{ Exposure history } \\
\hline Exposure to Wuhan & $122(45.5 \%)$ & $84(44.9 \%)$ & 0.899 \\
\hline Contact with confirmed or suspected patients & $130(48.5 \%)$ & $76(40.6 \%)$ & 0.097 \\
\hline Familial cluster & $93(34.7 \%)$ & $61(32.6 \%)$ & 0.644 \\
\hline Current smoking & $14(5.2 \%)$ & $20(10.7 \%)$ & 0.029 \\
\hline \multicolumn{4}{|l|}{ Condition } \\
\hline Any & $67(25.0 \%)$ & $82(43.9 \%)$ & $<0.001$ \\
\hline Hypertension & $26(9.7 \%)$ & $48(25.7 \%)$ & $<0.001$ \\
\hline Diabetes & 19(7.1\%) & $21(11.2 \%)$ & 0.125 \\
\hline Heart disease & $5(1.9 \%)$ & $5(2.7 \%)$ & 0.563 \\
\hline Chronic liver disease & $8(3.0 \%)$ & $14(7.5 \%)$ & 0.028 \\
\hline Chronic renal disease & $1(0.4 \%)$ & $2(1.1 \%)$ & 0.753 \\
\hline Cancer & $3(1.1 \%)$ & $3(1.6 \%)$ & 0.977 \\
\hline COPD & $0(0.0 \%)$ & $1(0.5 \%)$ & 0.411 \\
\hline Immunosuppression & $0(0.0 \%)$ & $1(0.5 \%)$ & 0.411 \\
\hline \multicolumn{4}{|l|}{ Signs and symptoms } \\
\hline Fever & $213(79.5 \%)$ & 164(87.7\%) & 0.022 \\
\hline Highest temperature $\left({ }^{\circ} \mathrm{C}\right)$ & & & 0.085 \\
\hline$<37.3$ & $55(20.5 \%)$ & $23(12.3 \%)$ & \\
\hline $37.3-38.0$ & $92(34.3 \%)$ & $80(42.8 \%)$ & \\
\hline $38.1-39.0$ & 101(37.7\%) & $72(38.5 \%)$ & \\
\hline$>39.0$ & $20(7.5 \%)$ & $12(6.4 \%)$ & \\
\hline Cough & $165(61.6 \%)$ & $136(72.7 \%)$ & 0.013 \\
\hline Sputum production & $87(32.5 \%)$ & $79(42.2 \%)$ & 0.033 \\
\hline Sore throat & $48(17.9 \%)$ & $20(10.7 \%)$ & 0.034 \\
\hline Nasal obstruction & $20(7.5 \%)$ & $5(2.7 \%)$ & 0.027 \\
\hline Myalgia & $32(11.9 \%)$ & $20(10.7 \%)$ & 0.681 \\
\hline Fatigue & $58(21.6 \%)$ & $35(18.7 \%)$ & 0.787 \\
\hline Gl symptoms ${ }^{a}$ & $36(13.4 \%)$ & $30(16.0 \%)$ & 0.437 \\
\hline Headache & $20(7.5 \%)$ & $23(12.3 \%)$ & 0.083 \\
\hline Incubation period (days) & $7(4-11)(n=86)$ & $7(4-10)(n=46)$ & 0.578 \\
\hline Days from illness onset to first medical visit(days) & $2(1-5)$ & $3(1-5)$ & 0.143 \\
\hline Days from illness onset to confirm the diagnosis(days) & $5(3-8)$ & $5(3-8)$ & 0.393 \\
\hline Days from illness onset to first hospitalization(days) & $4(2-7)$ & $4(3-8)$ & 0.491 \\
\hline Clinical Type & & & 0.004 \\
\hline Mild/ Moderate & 249(92.9\%) & $158(84.5 \%)$ & \\
\hline Severe/ Critical & 19(7.1\%) & $29(15.5 \%)$ & \\
\hline
\end{tabular}

Data are presented as medians (interquartile ranges, IQR), $\mathrm{n}(\%)$ and mean (SD)

Gl symptoms $s^{\mathrm{a}}$ include nausea, vomiting or diarrhea 
of patients in Group B was diagnosed as severe/critical types than from Group A ( $15.5 \%$ vs. $7.1 \%, P=0.004)$.

\section{Radiographic and laboratory findings}

The radiographic and laboratory findings of the patients are shown in Table 2. On admission, Group B showed a significantly lower rate of neutropenia $(12.8 \%$ vs. $23.9 \%$, $P=0.003)$ and a higher level of hemoglobin (143.23 g/L vs. $133.52 \mathrm{~g} / \mathrm{L}, P<0.001)$. Furthermore, Group B showed significantly elevated level of alanine aminotransferase (ALT) $(21.4 \%$ vs. $9.7 \%, P<0.001)$ and aspartate aminotransferase (AST) $(18.2 \%$ vs. $10.1 \%, P=0.013)$. In addition, the median levels of ALT, AST, and total bilirubin (TB) in Group B were significantly higher than those in Group A $(27 \mathrm{U} / \mathrm{L}$ vs. $18.4 \mathrm{U} / \mathrm{L}, P<0.001 ; 27 \mathrm{U} / \mathrm{L}$ vs. $23 \mathrm{U} / \mathrm{L}, P<0.001 ; 10.45 \mu \mathrm{mol} / \mathrm{L}$ vs. $8.90 \mu \mathrm{mol} / \mathrm{L}, P=$ 0.019 , respectively). The median level of serum sodium in Group B was significantly lower $(137.80 \mathrm{mmol} / \mathrm{L}$ vs. $138.60 \mathrm{mmol} / \mathrm{L}, P=0.005)$ than in Group A, and a significantly higher rate of hyponatremia was observed in Group B (38.0\% vs. $26.9 \%, P=0.012)$. Group B showed a significantly higher median level of serum creatinine (Scr) $\quad(68.25 \mu \mathrm{mol} / \mathrm{L}$ vs $61.00 \mu \mathrm{mol} / \mathrm{L}, \quad P<0.001)$, CK (76.00 U/L vs $63.00 \mathrm{U} / \mathrm{L}, P=0.004), \mathrm{LDH}(212.50 \mathrm{U} / \mathrm{L}$ vs $202.00 \mathrm{U} / \mathrm{L}, P=0.022)$, Glu $(6.29 \mathrm{mmol} / \mathrm{L}$ vs $5.58 \mathrm{mmol} /$ $\mathrm{L}, P<0.001)$, and CRP $(10.50 \mathrm{mg} / \mathrm{L}$ vs $6.10 \mathrm{mg} / \mathrm{L}, P<$ 0.001 ). According to the poor imaging findings during the disease course, the radiological findings showed that bilateral pneumonia was the most common in the two groups. In addition, increased prevalence of bilateral pneumonia and multiple mottling and ground-glass opacity in Group B were observed, although the difference was did not reach statistically significant $(P=0.053)$.

\section{Treatment and outcomes}

All 455 patients were isolated and treated in designated hospitals with supportive care and empiric medication (Table 3). The most common complication in the two groups was acute liver injury $(26.7 \%$ vs $15.3 \%$, respectively, $P=0.003)$. The rate of ARDS in Group B was higher than that in Group A $(8.0 \%$ vs $2.6 \%$, respectively, $P=0.003)$. The remaining complications did not show any statistical significance. Antiviral treatment was adopted for all of the patients except for one in Group A. These antiviral drugs included interferon- $\alpha$ sprays, arbidol hydrochloride capsules (2 tablets three times daily), lopinavir and ritonavir 2 tablets $(500 \mathrm{mg})$ twice daily, orally.Several treatment options, including interferon- $\alpha$ sprays + lopinavir/ritonavir + arbidol triple combination treatment, interferon- $\alpha$ sprays + lopinavir/ ritonavir combination treatment, interferon- $\alpha$ sprays + arbidol combination treatment, lopinavir/ritonavir + arbidol combination treatment and interferon- $\alpha$ sprays, arbidol, or lopinavir/ritonavir monotherapy, were available. The regimen of antiviral therapy during hospitalization and the number of days from illness onset to antiviral therapy did not differ significantly between the two groups. However, the median duration of antiviral therapy in Group B was significantly longer than in Group A (18 days vs. 16 days, $P=0.001$ ). With respect to supportive treatment, the Group B showed significantly higher rates of antibiotic therapy $(57.8 \%$ vs. $47.8 \%, P=0.036)$, corticosteroid therapy $(24.1 \%$ vs. $16.4 \%, P=0.043)$, and immunoglobulin therapy $(23.5 \%$ vs. $16.0 \%, P=0.046)$, but no significant was detected in mechanical ventilation, ECMO therapy and intensive care unit therapy in two groups.

All patients were discharged uneventfully. Group B showed significantly longer median of days from illness onset to SARS-CoV-2 negativity (18 days vs. 17 days, $P=$ 0.015 ), days of hospitalization (19 days vs. 17 days, $P=$ 0.003 ) and days from illness onset to discharge (23 days vs. 21 days, $P=0.008$ ). However, the duration of fever and days from first abnormal imaging findings to obvious absorption were non-significant.

\section{Clinical characteristics of patients infected with SARS- CoV-2 with $\mathrm{BMI} \geq 2 \mathbf{2 4}$}

For further investigating the clinical characteristics of imported COVID-19 patients in the overweight/obesity group (Group B), patients with $\mathrm{BMI} \geq 24$ were divided into two groups according to clinical types (mild/ moderate group vs severe/critical group). As shown in Table S1, mild group and severe/critical group comprised of 158 and 29 patients, respectively. The severe/critical group showed significantly higher rates of exposure to Wuhan $(69.0 \%$ vs. $40.5 \%, P=0.005)$, coexisting medical condition $(72.4 \%$ vs. $38.6 \%, P=0.001)$, hypertension $(41.4 \%$ vs. $22.8 \%, P=0.035)$, chronic liver disease $(27.6 \%$ vs. $3.8 \%, P<0.001)$, fever $(100.0 \%$ vs. $85.4 \%$, $P=0.028)$, myalgia( $24.1 \%$ vs. $8.2 \%, P=0.011)$ and fatigue ( $34.5 \%$ vs. $17.7 \%, P=0.039$ ), and the highest temperature $(P=0.008)$ as compared to the mild group.

The radiographic and laboratory findings (Table S2), and low levels of lymphocytes and albumin were observed in the severe/critical group $(P=0.001$ and $P=$ 0.014 , respectively), and higher rates of lymphopenia and hypoproteinemia were noted in the severe/critical group (31.0\% vs. $10.1 \%, P=0.002 ; 62.1 \%$ vs. $37.3 \%, P=0.013$, respectively). The severe/critical group showed significantly higher levels of serum sodium, Scr, CK, LDH, and CRP. An increased level of CK and LDH was observed in the severe/critical group as compared to the mild group $(31.0 \%$ vs. $8.9 \%, P=0.001 ; 58.6 \%$ vs. $25.9 \%, P<$ 0.001 , respectively). Also, a significantly number of patients presented multiple mottling and ground-glass opacity in the severe/critical group than the mild group $(P=0.019)$. 
Table 2 Radiographic and Laboratory Findings of COVID-19 Patients with Different BMI

\begin{tabular}{|c|c|c|c|}
\hline Characteristics & $\begin{array}{l}\text { BMI }<24(\text { Group A) } \\
(N=268)\end{array}$ & $\begin{array}{l}\mathrm{BMI} \geq 24(\text { Group B) } \\
(N=187)\end{array}$ & $P$ value \\
\hline \multicolumn{4}{|l|}{ Blood routine } \\
\hline Leukocytes ( $\times 10^{9} / L$; normal range $\left.4-10\right)$ & $4.50(3.68-6.00)$ & $4.95(3.91-6.04)$ & 0.076 \\
\hline$>10 \times 10^{9} / \mathrm{L}$ & $5(1.9 \%)$ & $3(1.6 \%)$ & 1.000 \\
\hline$<4 \times 10^{9} / \mathrm{L}$ & $92(34.3 \%)$ & $51(27.3 \%)$ & 0.111 \\
\hline Neutrophils $\left(\times 10^{9} / L\right.$; normal range $\left.2-7\right)$ & $2.78(2.02-3.96)$ & $3.10(2.41-4.10)$ & 0.286 \\
\hline$>7 \times 10^{9} / \mathrm{L}$ & $12(4.5 \%)$ & $6(3.2 \%)$ & 0.494 \\
\hline$<2 \times 10^{9} / \mathrm{L}$ & $64(23.9 \%)$ & $24(12.8 \%)$ & 0.003 \\
\hline Lymphocytes ( $\times 10^{9} / L ;$ normal range $\left.0.8-4\right)$ & $1.18(0.90-1.60)$ & $1.20(0.90-1.60)$ & 0.880 \\
\hline$<0.8 \times 10^{9} / \mathrm{L}$ & $40(14.9 \%)$ & $25(13.4 \%)$ & 0.641 \\
\hline Hemoglobin (g/L, normal range: male 131-172, female 113-151) & 133.52(16.11) & 143.23(16.11) & $<0.001$ \\
\hline Platelet $\left(\times 10^{9} / \mathrm{L} ;\right.$ normal range:100-300) & $191.00(145.00-228.00)$ & $181.50(154.00-218.50)$ & 0.528 \\
\hline$<100 \times 10^{9} / \mathrm{L}$ & $9(3.4 \%)$ & $5(2.7 \%)$ & 0.677 \\
\hline \multicolumn{4}{|l|}{ Coagulation function } \\
\hline International normalized ration (normal range $0.85-1.15$ ) & $1.01(0.97-1.08)$ & $1.01(0.97-1.08)$ & 0.951 \\
\hline \multicolumn{4}{|l|}{ Blood biochemistry } \\
\hline Albumin (g/L; normal range 40.0-55.0) & $41.13(4.08)$ & $41.61(4.12)$ & 0.827 \\
\hline$<40.0 \mathrm{~g} / \mathrm{L}$ & $91(34.0 \%)$ & $77(41.2 \%)$ & 0.116 \\
\hline Alanine aminotransferase (U/L; normal range: male 9-50, female $7-40$ ) & $18.40(13.00-27.00)$ & $27.00(18.25-42.75)$ & $<0.001$ \\
\hline$>50$ (male), > 40(female) U/L & 26(9.7\%) & $40(21.4 \%)$ & $<0.001$ \\
\hline Aspartate aminotransferase (U/L; normal range: male $15-40$, female $15-35)$ & $23.00(18.00-29.20)$ & $27.00(21.00-35.38)$ & $<0.001$ \\
\hline$>40$ (male), > 35(female) U/L & $27(10.1 \%)$ & $34(18.2 \%)$ & 0.013 \\
\hline Total bilirubin (umol/L; normal range 0-26.0) & $8.90(6.00-12.75)$ & $10.45(7.40-14.40)$ & 0.019 \\
\hline$>26.0 \mathrm{umol} / \mathrm{L}$ & $7(2.6 \%)$ & $6(3.2 \%)$ & 0.707 \\
\hline Serum potassium (mmol/L; normal range 3.5-5.3) & $3.85(3.62-4.15)$ & $3.80(3.60-4.08)$ & 0.259 \\
\hline$<3.5 \mathrm{mmol} / \mathrm{L}$ & $42(15.7 \%)$ & $35(18.7 \%)$ & 0.394 \\
\hline Serum sodium (mmol/L; normal range 137.0-147.0) & $138.60(136.9-140.5)$ & $137.80(135.6-139.7)$ & 0.005 \\
\hline$<137.0 \mathrm{mmol} / \mathrm{L}$ & $72(26.9 \%)$ & $71(38.0 \%)$ & 0.012 \\
\hline Blood urea nitrogen (mmol/L; normal range 3.1-8.0) & $3.54(2.85-4.47)$ & $3.75(2.99-4.60)$ & 0.135 \\
\hline Serum creatinine (umol/L; normal range male: $57-97$, female $41-73$ ) & $61.00(52.00-73.00)$ & $68.25(56.00-80.20)$ & $<0.001$ \\
\hline Creatine kinase (U/L; normal range: male40-200, female 50-130)) & $63.00(44.00-92.00)$ & $76.00(51.50-99.00)$ & 0.004 \\
\hline > 200 (male), > 130(female) U/L & $29(10.8 \%)$ & $23(12.3 \%)$ & 0.626 \\
\hline Lactate dehydrogenase (U/L; normal range 120-250) & $202.00(162.00-251.00)$ & $212.50(170.50-276.00)$ & 0.022 \\
\hline$>250 \mathrm{U} / \mathrm{L}$ & $64(23.9 \%)$ & $58(31.0 \%)$ & 0.091 \\
\hline Glucose (mmol/L; normal range 3.9-6.1) & $5.58(4.90-6.70)$ & $6.29(5.36-7.85)$ & $<0.001$ \\
\hline \multicolumn{4}{|l|}{ Infection-related biomarkers } \\
\hline C-reactive protein (mg/L; normal range $0-8$ ) & $6.10(1.60-14.67)$ & $10.50(4.00-24.20)$ & $<0.001$ \\
\hline Chest $\mathrm{x}$-ray/CT findings & & & 0.053 \\
\hline Normal & $21(7.8 \%)$ & $11(5.9 \%)$ & \\
\hline Unilateral pneumonia & $61(22.8 \%)$ & $25(13.4 \%)$ & \\
\hline Bilateral pneumonia & $117(43.7 \%)$ & $94(50.3 \%)$ & \\
\hline Multiple mottling and ground-glass opacity & $69(25.7 \%)$ & $57(30.5 \%)$ & \\
\hline
\end{tabular}

Data are presented as medians (interquartile ranges, IQR), $\mathrm{n}(\%)$ and mean (SD) 
Table 3 Treatments and outcomes of COVID-19 patients with Different BMI

\begin{tabular}{|c|c|c|c|}
\hline Characteristics & $\begin{array}{l}\mathrm{BMI}<24(\text { Group } \mathrm{A}) \\
(N=268)\end{array}$ & $\begin{array}{l}\mathrm{BMI} \geq 24(\text { Group } B) \\
(N=187)\end{array}$ & $P$ value \\
\hline \multicolumn{4}{|l|}{ Complications } \\
\hline Acute respiratory distress syndrome & $7(2.6 \%)$ & $15(8.0 \%)$ & 0.008 \\
\hline liver function abnormality & $41(15.3 \%)$ & $50(26.7 \%)$ & 0.003 \\
\hline Acute kidney injury & $0(0.0 \%)$ & $0(0.0 \%)$ & \\
\hline Shock & $0(0.0 \%)$ & $1(0.5 \%)$ & 0.411 \\
\hline \multicolumn{4}{|l|}{ Treatments } \\
\hline Antiviral treatment $(\mathrm{n}(\%))$ & $267(99.6 \%)$ & 187(100\%) & 0.403 \\
\hline Days from illness onset to antiviral therapy (days) & $5(3-8)$ & $5(3-8)$ & 0.926 \\
\hline Days of antiviral therapy & $16(13-21)$ & 18(14-23) & 0.001 \\
\hline Antiviral regimen (days) & & & 0.731 \\
\hline Interferon-a + Lopinavir/Ritonavir + arbidol & $159(59.6 \%)$ & $120(64.2 \%)$ & \\
\hline Interferon-a + Lopinavir/Ritonavir & $45(16.9 \%)$ & $27(14.4 \%)$ & \\
\hline Interferon- $a+$ arbidol & 19(7.1\%) & $13(7.0 \%)$ & \\
\hline Lopinavir/Ritonavir+arbidol & $33(12.4 \%)$ & $18(9.6 \%)$ & \\
\hline Others $^{a}$ & $11(4.1 \%)$ & $9(4.8 \%)$ & \\
\hline \multicolumn{4}{|l|}{ Supportive treatment $(\mathrm{n}(\%))$} \\
\hline Antibiotic therapy & $128(47.8 \%)$ & $108(57.8 \%)$ & 0.036 \\
\hline Use of corticosteroid & $44(16.4 \%)$ & $45(24.1 \%)$ & 0.043 \\
\hline Use of immunoglobulin & $43(16.0 \%)$ & $44(23.5 \%)$ & 0.046 \\
\hline mechanical ventilation & $2(0.7 \%)$ & $6(3.2 \%)$ & 0.109 \\
\hline CRRT & $0(0.0 \%)$ & $0(0.0 \%)$ & \\
\hline ECMO & $1(0.4 \%)$ & $0(0.0 \%)$ & 1.000 \\
\hline Admission to intensive care unit & $1(0.4 \%)$ & $2(1.1 \%)$ & 0.753 \\
\hline \multicolumn{4}{|l|}{ Clinical outcomes } \\
\hline Days from illness onset to SARS-CoV-2 RNA negative (days) & $17(13-21)$ & $18(14-25)$ & 0.015 \\
\hline Days of hospitalization (days) & $17(13-22)$ & 19(15-24) & 0.003 \\
\hline Days from illness onset to discharge (days) & $21(17-26)$ & 23(18-29) & 0.008 \\
\hline Days of fever (days) & $9(6-12)$ & $9(6-12)$ & 0.939 \\
\hline Days from first abnormal imaging findings to obvious absorption (days) & 13(10-17) & $13(10-16)$ & 0.115 \\
\hline
\end{tabular}

Data are presented as medians (interquartile ranges, IQR), $\mathrm{n}(\%)$ and mean (SD) Others ${ }^{\mathrm{a}}$ include interferon-a sprays, arbidol, and lopinavir/ritonavir monotherapy

Furthermore, the severe/critical group showed significantly higher rates of ARDS (44.8\% vs. $1.3 \%, P<$ $0.001)$, antibiotic therapy $(82.8 \%$ vs. $53.2 \%, P=$ $0.003)$, corticosteroid therapy $(72.4 \%$ vs. $15.2 \%, P<$ $0.001)$, immunoglobulin therapy $(69.0 \%$ vs. $15.2 \%$, $P<0.001)$, mechanical ventilation $(17.2 \%$ vs. $0.6 \%, P<$ $0.001)$ and admission to intensive care unit $(6.9 \%$ vs. $0.0 \%, P=0.023)$ than the mild group. Furthermore, the severe/critical group showed significantly longer median time as the number of days from illness onset to discharge ( 26 days vs. 23 days, $P=0.034$ ), duration of fever ( 12 days vs. 9 days, $P=0.029)$ and from first abnormal imaging findings to obvious absorption ( 16 days vs. 13 days, $P=0.005$ ) than the mild group. (Table S3).

\section{Risk factors predicted of progression to severe/critical} illness

The cohort of this study comprised of 48 severe/critical COVID-19. In the univariable logistic regression of epidemiological, clinical and laboratory variables, 25 risk factors were significantly associated with severe/critical type (Table S4). Multivariable logistic regression demonstrated that BMI (per $1 \mathrm{~kg} / \mathrm{m}^{2}$ increase) (OR: 1.168; 95\%CI: $1.050-1.298, P=0.004)$, exposure to Wuhan (OR: 4.214 ; 95\%CI: $1.888-9.408, P<0.001$ ), any coexisting medical condition (OR: 3.885; 95\%CI: $1.836-8.220$, $P<0.001$ ), highest temperature (OR: 2.521 ; 95\%CI: $1.446-4.395, P=0.001$ ), CRP (OR: 1.025 ; 95\%CI: $1.008-$ $1.042, P=0.003)$, and increased LDH (OR: 3.068 ; $95 \% \mathrm{CI}$ : 1.423-6.615, $P=0.004$ ) were independent risk factors 
associated with severe/critical illness (Table 4). For the sensitivity analysis, treating BMI as a categorical rather than continuous variable lead to similar results, showing a tendency for higher odds of progressing to severe/critically illness as higher BMI (OR: 1.20 per unit; 95\% CI: 1.09-1.33; $P=0.0040$ ). When adjusted for sex and age, the ratio of $\mathrm{BMI}>28$ compared to $\mathrm{BMI}<24$ was 3.70 (95\% CI 1.57-8.71, $P=0.0046$ ), and in the fully adjusted model, the odds of BMI as a clinical risk factor was 3.80 (95\% CI 1.32-10.93, $P=0.032$ ) (Table S5).

\section{Risk factors associated with high BMI}

This study comprised of 187 COVID-19 patients with $\mathrm{BMI} \geq 24$.According to Tables 1, 2 and 3, 26 risk factors were significantly associated with high BMI. Multivariable logistic regression showed that hemoglobin (OR: 1.031; 95\%CI: 1.017-1.046, $P<0.001$ ), ALT (OR: 1.038; 95\%CI: $1.020-1.057, P<0.001$ ), CRP (OR: 1.024; 95\%CI: $1.010-1.037, P<0.001)$, and Scr (OR: $1.010 ; 95 \% \mathrm{CI}$ : $1.002-1.019, P=0.020$ ) were independent associated factors with high BMI (Table 5).

\section{Discussion}

Several groups have discovered that overweight/obesity is correlated with the severity of illness and mortality in COVID-19 patients [23, 24]. However, those data are insufficient to reveal the clinical characteristics and outcomes of COVID-19 patients with overweight/obesity. Hence, we investigated the differences between patients with underweight/normal weight and patients with overweight/obesity in terms of clinical characteristics and the independent association of BMI with disease severity. According to these findings, patients with $\mathrm{BMI} \geq 24$ were mostly men, had smoking history, were severe/critical type, had acute/chronic liver injury and ARDS, longer hospitalization time, more number of days from illness onset to SARS-CoV-2 RNA negative, underwent prolonged anti-virus course, and had higher levels of ALT, AST, TB, Scr, CK, LDH, Glu, and CRP as compared to patients with $\mathrm{BMI}<24$. So, high $\mathrm{BMI}$ is an independent risk factor for severe/critical COVID-19 patients.

In this retrospective cohort study, 187 (41\%) COVID19 patients were overweight/obese. Commonly,

Table 4 Multivariable Analysis of Risk Factors associated for the Severe/Critical type COVID-19 patients

\begin{tabular}{lll}
\hline Risk Factors & Odds Ratio $(\mathbf{9 5} \% \mathbf{C l})$ & $\boldsymbol{P}$ value \\
\hline BMI (per $\mathbf{1 ~ k g} / \mathbf{m}^{\mathbf{2}}$ increase) & $1.168(1.050-1.298)$ & 0.004 \\
Exposure to Wuhan & $4.214(1.888-9.408)$ & $<0.001$ \\
Any coexisting medical condition & $3.885(1.836-8.220)$ & $<0.001$ \\
Highest temperature & $2.521(1.446-4.395)$ & 0.001 \\
CRP & $1.025(1.008-1.042)$ & 0.003 \\
LDH $(>\mathbf{2 5 0}$ vs. $\leq \mathbf{2 5 0})$ & $3.068(1.423-6.615)$ & 0.004 \\
\hline
\end{tabular}

Table 5 Multivariable Analysis of Risk Factors associated for COVID-19 patients with high BMI

\begin{tabular}{lll}
\hline Risk Factors & Odds Ratio $(\mathbf{9 5 \%} \mathrm{Cl})$ & $\boldsymbol{P}$ value \\
\hline Hemoglobin & $1.031(1.017-1.046)$ & $<0.001$ \\
ALT & $1.038(1.020-1.057)$ & $<0.001$ \\
Scr & $1.010(1.002-1.019)$ & 0.02 \\
CRP & $1.024(1.010-1.037)$ & $<0.001$ \\
\hline
\end{tabular}

overweight/obesity is closely related to increased morbidity and mortality to infectious diseases, and growing epidemiologic data can be cited in support of this conclusion $[15,18,19,25,26]$.

The current study also proved that overweight/obese patients were highly vulnerable and had poor health. We also observed that such patients had several pre-existing diseases, such as hypertension and chronic liver disease. The initial clinical symptoms of pulmonary inflammation, including fever, cough and sputum production, were common in overweight/obese patients.

In addition to clinical findings, the laboratory results showed that obese patients also experienced worse illnesses. Some biochemical indicators, including ALT, AST, TB, Scr, CK, LDH, Glu, and CRP, indicating the injury of liver, kidney, myocardium, normal glucose regulation, more active inflammation, were significantly elevated in the blood of overweight/obese patients. These findings were consistent with the extensive distribution of ACE2 [9-12]. Moreover, because of the high level of these indicators, the risk of developing multiple organs dysfunction/failure syndrome in patients with overweight/obese is increased. This theory was supported by the higher rates of antibiotic therapy, corticosteroid therapy, immunoglobulin therapy and admission to the intensive care unit.

Although the reasons for increased infection risk of obesity are diverse, obesity-induced adipose tissue inflammation is considered a key player in the pathogenesis of infectious diseases, which might also play a major role in COVID-19. The adipose tissue secretes a series of immune regulators, termed as adipokines, such as leptin and adiponectin, which connect metabolism and immune system functions [27]. Obese individuals, because of fat accumulation and the dysregulation of adipokine secretion, exhibit disrupted lymphoid tissue integrity, changes in cytokine synthesis, reduced antigen response, and diminished function of natural killer cells, dendritic cells, and macrophages [26]. These factors promote obese individuals to produce inflammatory autoimmune responses and increase their sensitivity to infectious diseases.

Furthermore, excessive cytokines, such as interleukin (IL)-6, IL-8, monocyte chemoattractant protein-1 (MCP1 ), and leptin produced by the dysfunctional adipocytes 
in obesity, leads to increased recruitment of macrophages. Interestingly, these cells produce abundant proinflammatory molecules, such as IL-1 $\beta$, IL- 6 , IL- 8 , and MCP-1 [28]. Finally, the cytokine storm causes a hyperinflammatory reaction, which aggravates the COVID-19 infection. On the other hand, a recent study showed that the high expression of ACE2 in the adipose tissue not only plays a positive role in reversing the ACE1-induced damage but also promotes viral entrance [29]. Therefore, whether the mechanism of ACE2 on the adipose tissue or intensive cytokine storm produced by the dysfunctional adipocytes worsens COVID-19 outcomes is yet to be elucidated.

Previously, several studies revealed that obese hosts exhibit delayed and inactivated antiviral responses to influenza virus infection, and they recover poorly from the disease [30-32]. In addition, the efficacy of antiviral drugs was reduced in this population. Also, similar changes were observed in COVID-19 patients with overweight/obesity. In this study, compared to underweight/normal individuals, obese individuals had longer hospitalization, SARS$\mathrm{CoV}-2$ shedding, and anti-virus course and a higher proportion of severe/critical type. Notably, with the extension of the disease course, the risk of transmission to others increases, suggesting that obesity may play a critical role in SARS-CoV-2 transmission.

In addition, according to our data, most imported COVID-19 patients with $\mathrm{BMI} \geq 24$ in Zhejiang province were male patients, with significantly older age consistent with previous findings in the Chinese population [33]. Moreover, due to a high number of male patients, overweight/obese patients consisted largely of smokers.

We also compared the clinical characteristics and outcome of mild and severe/critical COVID-19 patients with overweight/obese. Firstly, severe/critical COVID-19 patients had been exposed to Wuhan. Secondly, differing from previous studies, the current results found that severe/critical patients had a significantly higher rate of myalgia and fatigue, which might result from an additional body burden due to excess fat. Therefore, we should be cautious about overweight/obese COVID-19 patients with these symptoms. The remaining clinical characteristics and outcome, including laboratory results, radiographic findings, treatment outcomes, were similar to those described in previous studies $[34,35]$.

The risk factors for severe/critical COVID-19 patients were calculated by multivariable logistic regression analysis. The total six factors are presented in Table 4. In summary, high BMI, exposure to Wuhan, any coexisting medical condition, highest temperature, CRP and increased LDH were independent risk factors for severe/critical COVID-19 patients. These findings indicated that overweight/obese COVID-19 patients had deteriorated health. A recent study from Zhejiang, China, also showed that in patients with metabolism-associated fatty liver disease, obesity increases the risk of severe COVID-19 illness [36].

Nevertheless, the current study has some limitations. First, weight and height should be measured in every patient. However, in our study, the weight and height of patients admitted with severe/ critical type could not be measured. Second, although the risk factors for severe/ critical type of COVID-19 patients with overweight/ obesity were identified, it still lacked of a prediction model for disease progression. Third, as the patients were only from Zhejiang province, it might be valuable when clinical features related to COVID-19 at a national level would be summarized. However, due to the limited sample size, we require further substantiation of the results in future studies.

\section{Conclusions}

In summary, we reported the specific clinical characteristics and outcomes of imported COVID-19 patients with different BMIs. Contrasted with the imported COVID-19 patients with $\mathrm{BMI}<24$, high proportion of COVID-19 patients with $\mathrm{BMI} \geq 24$ in our study, especially those with elevated CRP and LDH, developed to severe type, with longer hospitalization duration and anti-virus course. In addition, high BMI was an independent risk factor for severe/critical COVID-19. Therefore, intensive attention should be paid to patients with high BMI to control the disease progression and the spread of the epidemic of COVID-19.

\section{Supplementary Information}

The online version contains supplementary material available at https://doi. org/10.1186/s12879-021-05818-0.

Additional file 1: Table S1. Demographic and Epidemiological Characteristics of COVID-19 Patients with $\mathrm{BMI} \geq 24$. Data are presented as medians (interquartile ranges, IQR), n (\%) and mean (SD).Gl symptoms* include nausea, vomiting and diarrhea.

Additional file 2: Table S2. Radiographic and Laboratory Findings of COVID-19 Patients with $\mathrm{BMI} \geq 24$. Data are presented as medians (interquartile ranges, $(Q R), n(\%)$ and mean (SD).

Additional file 3: Table S3. Treatments and outcomes of COVID-19 patients with $B M I \geq 24$. Data are presented as medians (interquartile ranges, IQR), n (\%) and mean (SD). Others* include interferon-a sprays, arbidol, and lopinavir/ritonavir monotherapy.

Additional file 4: Table S4. Univariable Analysis of Risk Factors associated for the Severe/Critical type COVID-19 patients.

Additional file 5: Table S5. Relationships between the BMI and Severe/ Critical using different models. Note: Model I adjusted for age, sex. Model II adjusted for age, sex, exposure to Wuhan, any coexisting medical condition, highest temperature, LDH, and C-reactive protein.

\section{Abbreviations}

COVID-19: Coronavirus disease 2019; SARS-CoV-2: Severe acute respiratory syndrome coronavirus 2; ARDS: Acute respiratory distress syndrome; ACE2: Angiotensin-converting enzyme 2; HIV: Human immunodeficiency virus; BMI: Body mass index; WHO: World health Organization; RTPCR: Reverse transcription-polymerase chain reaction; MERS-CoV: Middle east respiratory syndrome coronavirus; SD: Standard deviation; IQR: Interquartile 
range; Gl: Gastrointestinal; ALT: Alanine aminotransferase; AST: Aspartate aminotransferase; TB: Total bilirubin; Scr: Serum creatinine; CK: Creatine kinase; LDH: Lactate dehydrogenase; Glu: Glucose; CRP: C-reactive protein; ECMO: Extracorporeal membrane oxygenation; CRRT: Continuous renal replacement therapy; IL: Interleukin; MCP-1: Monocyte chemoattractant protein-1

\section{Acknowledgements}

We thank Health Commission of Zhejiang Province, China for coordinating data collection; Thanks to all the front-line medical staffs of Zhejiang Province for their bravery and efforts in COVID-19 prevention and control.

\section{Authors' contributions}

HJ: Conceptualization, Methodology, Writing-original draft. YY and JS: Conceptualization, Writing-review \& editing. HC: Methodology, Investigation, Writing-original draft. LY and YL: Formal analysis, Investigation, interpretation of data. SZ, CY, XZ, GY, JG, JL, SH, JH, YZ, and CJ: Investigation. All authors read and approved the final manuscript.

\section{Funding}

This work was supported by National Major Science and Technology Research Projects for the Control and Prevention of Major Infectious Diseases in China (2017ZX10202202). This funding source was involved in the design of the study, data analysis, interpretation of data and in writing the manuscript.

\section{Availability of data and materials}

The datasets used during the current study are available from the corresponding author on reasonable request.

\section{Ethics approval and consent to participate}

The study was approved by Clinical Research Ethics Committee of the First Affiliated Hospital, College of Medicine, Zhejiang University, and the need for informed consent was waived. The data used in this study was anonymized before its use. The Health Commission of Zhejiang province granted permissions which were required to access the raw data used in this study.

\section{Consent for publication}

Not applicable.

\section{Competing interests}

The authors declare that they have no competing interests.

Received: 24 July 2020 Accepted: 18 January 2021

Published online: 05 February 2021

\section{References}

1. Cossarizza A, De Biasi S, Guaraldi G, Girardis M, Mussini C. SARS-CoV-2, the virus that causes COVID-19: Cytometry and the new challenge for Global Health. Cytometry A. 2020;97(4):340-3.

2. Ayittey FK, Ayittey MK, Chiwero NB, Kamasah JS, Dzuvor C. Economic impacts of Wuhan 2019-nCoV on China and the world. J Med Virol. 2020; 92(5):473-5.

3. Armocida B, Formenti B, Ussai S, Palestra F, Missoni E. The Italian health system and the COVID-19 challenge. Lancet Public Health. 2020;5(5):e253.

4. Zhu N, Zhang D, Wang W, et al. A novel coronavirus from patients with pneumonia in China, 2019. N Engl J Med. 2020;382(8):727-33.

5. Phelan AL, Katz R, Gostin LO. The novel coronavirus originating in Wuhan, China: challenges for Global Health governance. Jama. 2020. https://doi.org/ 10.1001/jama.2020.1097.

6. Chen N, Zhou M, Dong X, et al. Epidemiological and clinical characteristics of 99 cases of 2019 novel coronavirus pneumonia in Wuhan, China: a descriptive study. Lancet (London, England). 2020;395(10223):507-13.

7. World Health Organization. Weekly epidemiological update - 19 January 2021.Available at: https://www.who.int/publications/m/item/ weeklyepidemiological-update---19-january-2021. Accessed 27 Jan 2021.

8. Letko M, Marzi A, Munster V. Functional assessment of cell entry and receptor usage for SARS-CoV-2 and other lineage B betacoronaviruses. Nat Microbiol. 2020;5(4):562-9.

9. Gu J, Korteweg C. Pathology and pathogenesis of severe acute respiratory syndrome. Am J Pathol. 2007;170(4):1136-47.
10. Guo Y, Korteweg C, McNutt MA, Gu J. Pathogenetic mechanisms of severe acute respiratory syndrome. Virus Res. 2008;133(1):4-12.

11. Xiao F, Tang M, Zheng X, Liu Y, Li X, Shan H. Evidence for gastrointestinal infection of SARS-CoV-2. Gastroenterology. 2020;158(6):1831-1833.e3.

12. Zou X, Chen K, Zou J, Han P, Hao J, Han Z. Single-cell RNA-seq data analysis on the receptor ACE2 expression reveals the potential risk of different human organs vulnerable to 2019-nCoV infection. Front Med. 2020;14(2):185-92.

13. Jia X, Yin C, Lu S, Chen Y, Liu Q, Bai J, Lu Y. Two things about COVID-19 might need attention. Preprint at https://www.preprints.org/manuscript/202 002.0315/v1. Accessed 27 Jan 2021

14. Pinheiro TA, Barcala-Jorge AS, Andrade JMO, et al. Obesity and malnutrition similarly alter the renin-angiotensin system and inflammation in mice and human adipose. J Nutr Biochem. 2017:48:74-82

15. Bourgeois C, Gorwood J, Barrail-Tran A, et al. Specific biological features of adipose tissue, and their impact on HIV persistence. Front Microbiol. 2019; 10:2837.

16. World Health Organization. Fact sheets of obesity and overweight. Available at: https://www.who.int/news-room/fact-sheets/detail/obesity-andoverweight. Accessed 27 Jan 2021.

17. Andersen CJ, Murphy KE, Fernandez ML. Impact of obesity and metabolic syndrome on immunity. Adv Nutri. 2016;7(1):66-75.

18. Van Kerkhove MD, Vandemaele KA, Shinde V, et al. Risk factors for severe outcomes following 2009 influenza a (H1N1) infection: a global pooled analysis. PLoS Med. 2011;8(7):e1001053.

19. Sun Y, Wang Q, Yang G, Lin C, Zhang Y, Yang P. Weight and prognosis for influenza $A(\mathrm{H} 1 \mathrm{~N} 1)$ pdm09 infection during the pandemic period between 2009 and 2011: a systematic review of observational studies with metaanalysis. Infect Dis. 2016:48(11-12):813-\#.

20. Huang C, Wang Y, Li X, et al. Clinical features of patients infected with 2019 novel coronavirus in Wuhan, China. Lancet. 2020;395(10223):497-506.

21. National Health Commission. Diagnosis and Treatment Protocol for COVID19 (Tentative 8th Edition). Available at: http://regional.chinadaily.com.cn/ pdf/DiagnosisandTreatmentProtocolforCOVID-1 9Patients(Tentative8thEdition).pdf. Accessed 13 Jan 2021.

22. Drafting committee of Chinese consensus on overweight/obesity medical nutrition therapy. Chinese consensus on overweight/obesity medical nutrition therapy (2016). Chin J Diabetes Mellitus. 2016;8(9):525-40.

23. Peng YD, Meng $K$, Guan $H Q$, et al. Clinical characteristics and outcomes of 112 cardiovascular disease patients infected by 2019-nCoV. Zhonghua Xin Xue Guan Bing Za Zhi 2020; 48(0): E004.

24. Liu M, He P, Liu HG, et al. Clinical characteristics of 30 medical workers infected with new coronavirus pneumonia. Zhonghua Jie He He Hu Xi Za Zhi. 2020:43(3):209-14

25. Huttunen R, Syrjänen J. Obesity and the risk and outcome of infection. Int J Obes. 2013;37(3):333-40

26. Dobner J, Kaser S. Body mass index and the risk of infection - from underweight to obesity. Clin Microbiol Infect. 2018;24(1):24-8.

27. Carbone F, La Rocca C, De Candia P, Procaccini C, Colamatteo A, Micillo T, De Rosa $V$, Matarese $G$. Metabolic control of immune tolerance in health and autoimmunity. Semin Immunol. 2017;28(5):491-504.

28. Korakas E, Ikonomidis I, Kousathana F, et al. Obesity and COVID-19: immune and metabolic derangement as a possible link to adverse clinical outcomes. Am J Physiol Endocrinol Metab. 2020;319(1):E105-9.

29. Caci G, Albini A, Malerba M, Noonan DM, Pochettiand P, Polosa R. COVID-19 and obesity: dangerous liaisons. J Clin Med. 2020;9(8):2511.

30. Gerberding JL, Morgan JG, Shepard JA, Kradin RL. Case records of the Massachusetts General Hospital. Weekly clinicopathological exercises. Case 9-2004. An 18-year-old man with respiratory symptoms and shock. N Engl J Med. 2004:350(12):1236-47.

31. Fleury $H$, Burrel $S$, Balick Weber $C$, et al. Prolonged shedding of influenza $\mathrm{A}(\mathrm{H} 1 \mathrm{N1})$ vvirus: two case reports from France 2009. Euro Surveill. 2009; 14(49):19434.

32. Nakajima N, Hata S, Sato $Y$, et al. The first autopsy case of pandemic influenza (a/H1N1pdm) virus infection in Japan: detection of a high copy number of the virus in type II alveolar epithelial cells by pathological and virological examination. Jpn J Infect Dis. 2010;63(1):67-71.

33. Jia AH, Xu SY, Ming J, Zhou J, Guo JH, Liu C, Hao PR, Ji QH. Epidemic characteristics of obesity in China under various diagnostic criteria. Chin J Diabetes Mellitus. 2017;9(4):221-5.

34. Guan WJ, Ni ZY, Hu Y, et al. Clinical characteristics of coronavirus disease 2019 in China. N Engl J Med. 2020;382(18):1708-20. 
35. Wang D, Hu B, Hu C, et al. Clinical characteristics of 138 hospitalized patients with 2019 novel coronavirus-infected pneumonia in Wuhan, China. Jama. 2020;323(11):1061-9.

36. Zheng $\mathrm{Kl}$, Gao F, Wang XB, et al. Obesity as a risk factor for greater severity of COVID-19 in patients with metabolic associated fatty liver disease. Metabolism. 2020. https://doi.org/10.1016/j.metabol.2020. 154244.

\section{Publisher's Note}

Springer Nature remains neutral with regard to jurisdictional claims in published maps and institutional affiliations.

Ready to submit your research? Choose BMC and benefit from:

- fast, convenient online submission

- thorough peer review by experienced researchers in your field

- rapid publication on acceptance

- support for research data, including large and complex data types

- gold Open Access which fosters wider collaboration and increased citations

- maximum visibility for your research: over $100 \mathrm{M}$ website views per year

At BMC, research is always in progress.

Learn more biomedcentral.com/submissions 